University of Nebraska - Lincoln

DigitalCommons@University of Nebraska - Lincoln

$2-2011$

\title{
More Ornamented Males Exhibit Increased Predation Risk and Antipredatory Escapes, but not Greater Mortality
}

\author{
Kasey D. Fowler-Finn \\ University of Nebraska-Lincoln, kasey.fowlerfinn@slu.edu \\ Eileen Hebets \\ University of Nebraska-Lincoln, ehebets2@unl.edu
}

Follow this and additional works at: https://digitalcommons.unl.edu/bioscihebets

Part of the Behavior and Ethology Commons

Fowler-Finn, Kasey D. and Hebets, Eileen, "More Ornamented Males Exhibit Increased Predation Risk and Antipredatory Escapes, but not Greater Mortality" (2011). Eileen Hebets Publications. 37.

https://digitalcommons.unl.edu/bioscihebets/37

This Article is brought to you for free and open access by the Papers in the Biological Sciences at DigitalCommons@University of Nebraska - Lincoln. It has been accepted for inclusion in Eileen Hebets Publications by an authorized administrator of DigitalCommons@University of Nebraska - Lincoln. 


\title{
More Ornamented Males Exhibit Increased Predation Risk and Antipredatory Escapes, but not Greater Mortality
}

\author{
Kasey D. Fowler-Finn and Eileen A. Hebets \\ School of Biological Sciences, University of Nebraska-Lincoln, Lincoln, NE, USA \\ Corresponding author - K. D. Fowler-Finn, current address: University of Wisconsin, \\ Milwaukee Lapham Hall, 3209 N Maryland Ave, Milwaukee, WI 532I I, USA; \\ email kaseyff@uwm.edu
}

\begin{abstract}
Secondary sexual traits not only confer benefits to their bearer through increased mate acquisition, but may also have inherent costs, including the attraction of predators. Here, we examined the relationship between conspicuous secondary sexual traits and predation costs using two male morphs of Schizocosa wolf spiders: brushlegged and non-ornamented. In the field, we ran two predation experiments using artificial enclosures to directly test mortality costs of predation on the two male morphs. Using a natural predator, a larger wolf spider in the genus Hogna, we found no difference in predation on brush-legged vs. non-ornamented males. However, predation was depends on environmental conditions. More individuals were preyed upon at night (vs. during the day) and on rock litter (vs. leaf litter), but the two male morphs were preyed upon equally to each other across environmental treatments. A laboratory experiment incorporated staged interactions between a single predator (Hogna) and each male morph to examine finer details of predation events. Again, we found no differential mortality between brush-legged and non-ornamented males. However, brush-legged males were attacked sooner and were more likely to escape the attack. Our results show an association between sexual ornamentation and predation risk as well as escape behavior.
\end{abstract}

\section{Introduction}

Males often gain mates by displaying conspicuous ornamentation and courtship (Andersson 1994), but these traits also have inherent costs associated with their maintenance and production, including the attraction of predators. Predation can exert strong selection on male traits in opposition to female mate choice (Burk 1982; Cade 1975; Endler 1992; Magnhagen 1991; Zuk \& Kolluru 1998). Risk of predation is often greater for preferred males - those with the most attractive call characteristics (frogs, Ryan \& Tuttle 1982), brighter colors (fish, Endler 1983; fish, Godin \& McDonough 2003), or patterns highly contrasting the background (fish, Endler 1980; lizards, Husak et al. 2006; lizards, Stuart-Fox et al. 2003). The evolution of male secondary sexual traits therefore represents a balance between increasing mate acquisition and decreasing predation risk.

Selection has resulted in the evolution of various ways to reduce predation risk for males. High predation risk can select for the evolution of less conspicuous traits (Kwiatkowski 2003; Stuart-Fox et al. 2004), and/or the loss of display components (Zuk et al. 2006). Changing the timing, placement on body, and detection distance of traits can ensure detectability by females while minimizing the attraction of predators (Endler 1991; Cummings et al. 2008). Predation risk could also be minimized as a result of the facultative expression of coloration or courtship behaviors (Godin 1995; Candolin 1998). Within a population, males may also vary in coloration, morphology, and courtship behavior and in the associated mating success and predation risk - 
one male phenotype may benefit from short-term mating success gained as a result of competition for mates, but suffer increased costs associated with predation (e.g. Alcock 1995, 1996). These costs include higher predation and increased predation risk translating into higher energy expenditure or lost opportunities necessarily incurred through escaping or avoiding detection (Cresswell 2008). However, predation costs are often assumed rather than directly tested (Kotiaho 2001), and the mechanics of the relationship between predation and sexual ornamentation/courtship are not necessarily straightforward - costs may be indirect or difficult to identify, or the level of risk can depend on the environmental background (Endler 1993).

Here, we test the hypothesis that males differing in ornamentation and courtship also differ in costs of predation. We additionally tested whether predation in the field differs between males and females. A field-based approach to measuring costs incorporates the varying environmental conditions under which the spiders experience predation pressure. However, measuring mortality by predation in the field inherently cannot account for differences among males in predation risk and/or anti-predator behavior, as these two factors may interact to determine observed mortality. Such differences are crucial to our understanding of the relationship between secondary sexual traits and costs of predation, as some males may be at higher risk, but may offset this risk by exhibiting phenotype-specific behaviors, such as escapes. We take a comprehensive approach to assessing costs: we measure predation under varying environmental conditions in the field and controlled-laboratory conditions, assess risk of predation, and test for a relationship between predation risk and antipredatory escapes. A clear test of these costs would benefit from an experimental system in which males show discrete variation in ornamentation and courtship, as costs among males differing discretely in secondary sexual traits are more easily measured in comparison to males showing continuous variation. Additionally, the system should encompass different male morphs that occur syntopically and share both general ecology and predator regime.

Here, we determine if differences in secondary sexual traits correspond to differences in costs sustained by predation using a population of Schizocosa wolf spiders in Mississippi consisting of brush-legged males and non-ornamented males (Hebets \& Vink 2007). The two male phenotypes display discrete differences in sexual ornamentation and courtship and are virtually identical in morphology and behavior to two previously described sister species -Schizocosa ocreata (brush-legged) and S. rovneri (non-ornamented). S. ocreata males have large black brushes on their forelegs and a highly active courtship display involving body bounces, leg arches, and jerky legs taps in association with a unique seismic display (Hentz 1844; Uetz \& Denterlein 1979). In contrast, S. rovneri males lack any foreleg ornamentation and have a more stationary courtship display that consists of a body bounce associated with a unique seismic signal (Uetz \& Denterlein 1979; Uetz \& Dondale 1979). Although behavioral isolation between brush-legged and non-ornamented males has been demonstrated in the Ohio Valley (Stratton \& Uetz 1981), the precise taxonomic status of brush-legged and non-ornamented males in the mixed population used in this study is uncertain - behavioral and mitochondrial data suggest that they form a single interbreeding population (Hebets \& Vink 2007), and no detectable genetic differentiation has been found between them (Fowler-Finn 2009). We refer to them as brush-legged and non-ornamented morphs in their syntopic occurrence in Mississippi.

Numerous laboratory studies using $S$. ocreata and $S$. rovneri have demonstrated that brushes confer a mating advantage (McClintock \& Uetz 1996; Scheffer et al. 1996; Uetz \& Roberts 2002). Additionally, a prior study using spiders from the mixed Mississippi population of brush-legged and non-ornamented males has also demonstrated a likely mating advantage for brushlegged males-females exposed to courtship of either male morph as subadults (a likely occurrence in the field as males mature before females) were more likely to mate with brush-legged males upon maturation, whereas naive females mated equally with either male morph (Hebets \& Vink 2007). Despite their apparent mating advantage, brush-legged $S$. ocreata males have also previously been shown to be more visually conspicuous to potential predators - videos of spiders with brushes and/or enlarged brushes displaying the active brush-legged courtship were more quickly oriented to and attacked by predators (Pruden \& Uetz 2004; Roberts et al. 2007; Roberts \& Uetz 2008). It is reasonable to hypothesize that the brush-legged males in the mixed Mississippi population also suffer this increased conspicuousness to predators. Using both field and laboratory-based studies, we directly examine the relationship between incurred predation, predation risk, and antipredatory escape behavior and secondary sexual traits in an effort to improve our understanding of the general relationship between ornamentation and predation costs. 


\section{Methods}

\section{Spiders}

\section{Schizocosa males (prey)}

We collected subadult individuals from leaf litter and rock litter at the University of Mississippi's campus greenhouse in Lafayette county, MS, USA on April 14-16, 2006 for the field experiments, and April 19-20, 2007 for the laboratory experiment (see below). Individuals were brought to the laboratory at the University of Nebraska-Lincoln and were housed individually in $6 \times 6 \times 8 \mathrm{~cm}$ Amac plastic boxes and maintained on a 12-h light/12-h dark cycle. Individuals were fed two crickets approximating their body size each week and were provided water ad libitum. The date of maturation for each individual was recorded and upon maturation, the sex and morph of males (brush-legged vs. non-ornamented) was recorded. Allowing individuals to mature in the laboratory ensured that they were virgins, and thus removed any potential effects of sexual experience on behavior at the time of experimentation. For the field experiments, the spiders were transported back to Mississippi a week before experimentation.

\section{Hogna spiders (predators)}

For predators, we used larger bodied wolf spiders from the genus Hogna ( $H$. georgicola and H. lenta) found at our mixed Schizocosa population site. Hognaknown to prey upon various invertebrates - are generally accepted to be a major predator of smaller wolf spiders (Wagner \& Wise 1996; Marshall \& Rypstra 1999; Persons \& Rypstra 2001; Persons et al. 2001, 2002; Rypstra \& Samu 2005), and have been observed at multiple instances attacking and/or eating Schizocosa in the field (K. D. Fowler-Finn and G. E. Stratton, pers. obs.). As mature male spiders often decrease foraging rate in place of increased mate searching and courtship (Foelix 1996), we only used females as our predators. For the field experiments, we collected adult and large subadult female Hogna (19 H. georgicola and $3 \mathrm{H}$. lenta) May 9-12, 2005, from the experimental field site as well as from three additional locations within 15 miles. We did not feed the Hogna after their capture 2-4 d prior to the field experiments. For the laboratory experiment, conducted the following year, Hogna individuals (35 H. georgicola) were collected from the field May 19-21, 2007, and brought back to the laboratory, housed individually in $9 \times 9 \times 11 \mathrm{~cm}$ Amac plastic boxes, and maintained on the same light:dark cycle as the Schizocosa used in the experiment (see above). Because we housed the Hogna spiders in the laboratory experiment long-term, we used the following feeding regime: all individuals were initially fed 2-3 adult crickets, to equalize hunger levels among individuals, then one adult cricket approximating their body size once a week until experimentation. The average weight of the Hogna used in these studies was almost 15 times that of Schizocosa (average weight \pm SE Hogna $=0.778 \pm 0.042 \mathrm{~g}$; average weight \pm SE Schizocosa $=0.055 \pm 0.001 \mathrm{~g}$ ).

\section{Experimental Design}

We conducted a series of experiments to test for differences between brush-legged and non-ornamented males in mortality costs, predation risk, and antipredatory escapes. The first two experiments were conducted in the field and were designed to elucidate differences between male morphs in mortality due to predation, as well as environmental effects on morph-specific predation. The third experiment was conducted in the laboratory and tested for predation in a controlled setting in addition to differences among male morphs in predation risk and antipredatory escapes.

\section{Field Experiment 1: Small Enclosures}

In order to determine whether predation imposed by Hogna wolf spiders differs between brush-legged and non-ornamented males, and between males and females, we constructed field enclosures that were placed near the University of Mississippi greenhouse in Oxford, MS, USA. The circular enclosures were constructed from aluminum flashing and measured $43 \mathrm{~cm}$ in diameter and $15 \mathrm{~cm}$ in height. Wolf spiders in the genera Hogna and Schizocosa lack the specialized hairs that enable climbing of smooth surfaces (Foelix 1996), and thus the aluminum flashing prevented our test spiders from entering and exiting the arenas, while still allowing movement of other spiders and invertebrates.

In addition to overall predation rates, we were interested in differences in predation across environmental conditions - specifically day vs. night and leaf litter vs. rock litter substratum (two substrata on which Schizocosa naturally occur at this site). Our $2 \times 2$ full factorial design included a set of four replicates for all combinations of environmental conditions (leaf litter/night; leaf litter/day; rock litter/night; rock litter/day; Figure 1). The substrate was standardized at $5-8 \mathrm{~cm}$ in depth. All leaf litter enclosures were buried $3-4 \mathrm{~cm}$ into the ground 


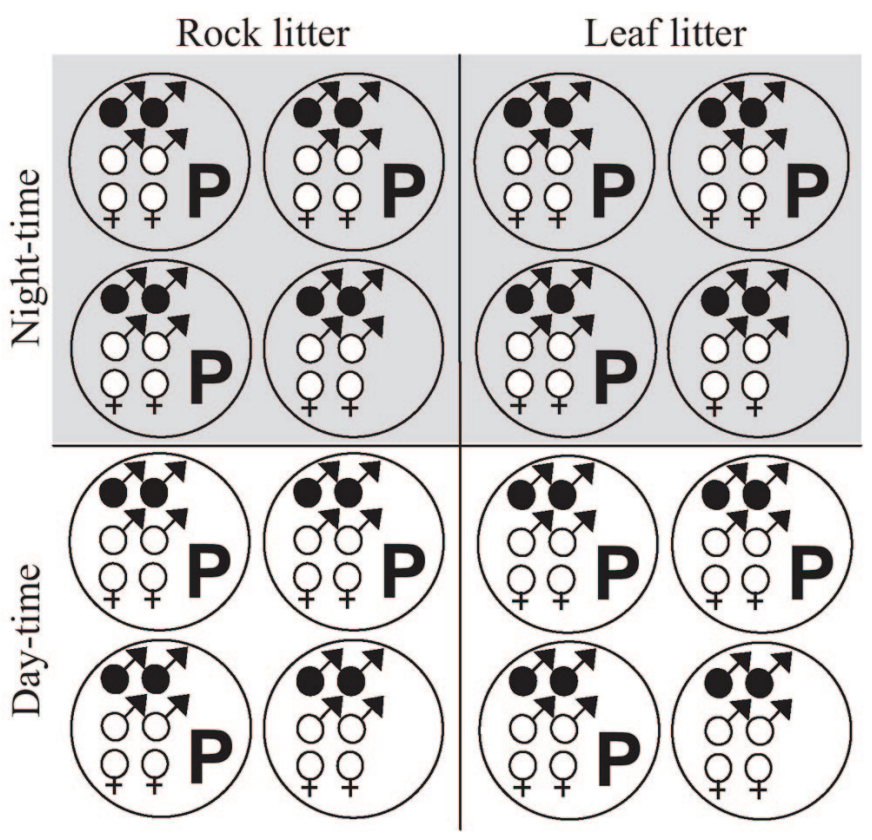

Figure I. Schematic showing the experimental design for Field Experiment I. Six spiders were in each enclosure, with a predator (represented by a P) added to 12 enclosures. Eight enclosures were on rock litter, eight enclosures were on leaf litter, eight were daytime enclosures and eight were night-time enclosures. Females are represented by the female sign, brush-legged males by the blackfilled male sign and non-ornamented males by the white-filled male sign. The figure does not represent the spatial arrangement of the enclosures in the field.

to prevent spiders from exiting. The rock litter enclosures required the addition of plastic garden sheet secured to the bottom edge of the enclosure to prevent spiders from exiting through crevices between rocks. The trials were conducted over two 12-h time periods night replicates from 20:00 to 08:00 on May 11-12, 2006, and day replicates from 08:00-20:00 on May 13, 2006. The weather during the trials represented typical conditions for the mating season - temperatures $\sim 27-32^{\circ} \mathrm{C}$, humidity of $60-90 \%$, and no rain.

We ensured that all enclosures were void of Schizocosa and Hogna wolf spiders prior to the start of each 12-h trial. We released six Schizocosa into each enclosure (two brush-legged males, two non-ornamented males and two females) and allowed them to acclimate $5 \mathrm{~min}$ before releasing a single Hogna into the enclosures. For each set of replicates (e.g. leaf litter/night; leaf litter/ day; rock litter/night; rock litter/day), we had three enclosures with a predator and an additional enclosure without a predator to ensure our predator treat- ment was effective and the Hogna had an effect on spider survival (Figure 1). Although we would have liked to have had a greater number of enclosures lacking a predator, and increased sample size overall, we were constrained by the number of animals we had and the difficulty of running a large-scale field experiment in a short time period. Six Schizocosa per arena reflects field densities, which often exceed three spiders per $100 \mathrm{~cm}^{2}$ (misprinted in Hebets \& Vink 2007). Including mature females helped ensure that males courted (see General observations), a critical aspect of our design as it is the different courtship displays in conjunction with different ornamentation that have been suggested to influence predator detection (Pruden \& Uetz 2004). Malemale competition is not highly ritualized, nor important in determining mating (Delaney et al. 2007), so although male-male interactions could potentially attract predators, courtship is much more likely to be important in determining predation risk. The predator used was a single female $H$. georgicola, with the exception of two enclosures where a single mature female $H$. lenta was used (rock litter/night and rock litter/day enclosures) due to insufficient numbers of $H$. georgicola.

All Schizocosa spiders to be used in the experiment were marked on their cephalothorax 2-6 $\mathrm{d}$ before experimentation with Deco paint pens for individual identification. This allowed us to detect any potential behavioral patterns among individuals as well as to ensure individuals re-captured from the arenas were experimental animals. There was no bias in predation associated with the color with which an individual was marked $(p=0.738)$. All individuals successfully captured a cricket the day following marking, and marking had no observable effects on their behavior. Two days prior to experimentation, all Schizocosa individuals were fed one cricket to standardize hunger levels.

\section{General observations}

During the course of the experiment, the variable measured was the number of Schizocosa individuals remaining in the enclosure. For the night-trial enclosures, we censused every enclosure approximately every hour from 20:00 to 01:00 in order to determine the first spider and first male morph preyed upon: we censused again at 04:00 to monitor for mating activities. We easily located night-time enclosure spiders during a trial by eye-shine using a headlamp. The leaf litter night-trial enclosures were monitored throughout the 12-h period using visual searching with headlamping for eyeshine and minimal manipulation of the substrate. We noted no change in behavior based 
on the methodology. We censused the day-time enclosures only after the first hour as we found that searching caused too much disturbance to the enclosures. As a result of differential censusing between treatments, we made no attempt to compare observations recorded during the trials between day-times and day-time enclosures. Two spiders were injured during the daytime census and these individuals were excluded from all future analyses. For both trials, we conducted final censuses at the end of the 12-h period-08:00 for night enclosures and 20:00 for day enclosures. For the final census, all substrate within each enclosure was removed and sorted to ensure that all spiders were recovered. Removal of the substrate was the most effective way of ensuring capture of all test individuals, as final censuses were conducted during daylight hours, making headlamp use and eyeshines impossible. We documented courtship activity, copulations and predation events throughout the censuses. We recorded what the Hogna were eating as well as if there was activity of other predators.

\section{Field Experiment 2: Large Enclosures}

The ratio of Hogna to Schizocosa in our first field enclosure experiment was artificially higher than that of normally found in the field (K. D. Fowler-Finn, pers. obs.), potentially leading to unnaturally high predation, which could dilute observable differences in predation between male morphs. We therefore conducted a second experiment using larger enclosures, in which the ratio of individuals approximated natural field densities at this site, and measured predation over a longer time-period. Because we were interested in patterns of predation between male morphs and not necessarily overall natural rates of predation in the field, this experiment would ensure that the close confinement of the predators with prey in small enclosures did not dilute the influence of male morph on risk of predation. Seven 2-m diameter enclosures were constructed on only the leaf litter substrate (the rock litter area was unable to accommodate the larger enclosures due to the shape of the area as well as obstacles within). The litter ranged from naturally found depths of approx. 5-20 cm throughout the enclosures. Twelve Schizocosa individuals were placed in each of the seven enclosures (i.e. four females, four brushlegged males and four non-ornamented males per enclosure resulting in 84 Schizocosa in total). In six of the seven enclosures a Hogna predator was present, and in one a predator was absent. These Hogna were different individuals from those used in the first set of enclosures. Ideally, we would have liked to have more enclosures without predators, but because we did not have enough animals, we used the absence of a predator in one enclosure to ensure the predator treatment was successful by providing a baseline.

Individuals were marked and released in the same manner as the small enclosure experiment. We ran all seven enclosures simultaneously starting at 02:00 on 11 May 2006 and made behavioral observations during hours three and five of the 24-h test. All seven enclosures were censused $24 \mathrm{~h}$ later (see section Experiment 1 for census procedures). At the end of the experiment, we visually searched for eye-shine using a headlamp in each enclosure for $10 \mathrm{~min}$. This process was repeated three times for a total of $30 \mathrm{~min}$ per enclosure. The final $5 \mathrm{~min}$ of searching in each enclosure did not result in the recovery of additional individuals, indicating we had collected all the spiders that remained at the end of the trial.

\section{Experiment 3: Predator-Prey Interactions}

To determine if both risk (measured as the latency to attack and capture) and likelihood of escaping an attack differed between male morphs, we staged live predator-prey interactions between a single $H$. georgicola and brush-legged $(n=26)$ or non-ornamented $(n=25)$ males in a controlled environment in the laboratory. As the majority of predation by Hogna predators occurs at night (see below), all trials were conducted a minimum of 30 min after the onset of the spiders' dark period (between 19:45 and 01:00 h) June 4-23, 2007. All trials were conducted in a dark laboratory room with minimal light from the hallway that entered the room around the doorframe. Trials were video-recorded using a nightshot Sony DVD Handycam (Sony Electronics Inc., San Diego, CA, USA) and infrared illumination and were observed real-time through the camcorder. Attacks by Hogna spiders and escapes by brush-legged and non-ornamented males were dictated into an Optimus microcassette voice recorder and later transcribed.

Predator-prey interactions were conducted in a large testing arena measuring $78 \times 15 \times 15 \mathrm{~cm}$ (Figure 2). The size of the arena allowed ample opportunity for the Schizocosa to escape from and avoid the predator. The arena walls were constructed from smooth plastic to prevent the exit of either predator or prey. In order to simulate natural substrate while still enabling detailed observation and standardization across trials, the bottom 


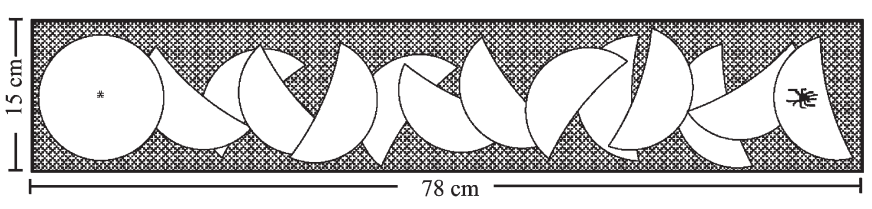

Figure 2. Schematic, drawn to scale, showing the experimental design for Experiment 3. Peat moss substrate with filter paper "leaves." Male Schizocosa were introduced into the arena onto filter paper impregnated with female silk to elicit courtship.

of the arena was filled with $1 \mathrm{~cm}$ of peat moss substrate, and 14 filter paper 'leaves' $(12.5 \mathrm{~cm}$ half circles of filter paper) were laid haphazardly and partially overlapping throughout the arena (Figure 2).

The Hogna predators were starved for a minimum of $7 \mathrm{~d}$ before use to increase motivation to attack, and all Hogna and Schizocosa spiders were weighed immediately before a trial. At the beginning of a trial, a single Hogna spider and single Schizocosa male (either brushlegged or non-ornamented) were introduced to opposite ends of the container approx. $60 \mathrm{~cm}$ apart and allowed to acclimate for $1 \mathrm{~min}$ under 8.5 -cm-diameter acetate barriers. The Schizocosa males were introduced onto a $12.5-\mathrm{cm}$ diameter circle of filter paper impregnated with female silk to induce courtship. If the male did not court by the end of the 1-min acclimatization period, the trial was delayed until courtship commenced. This design removed the possibility of differential time delays in the initiation of courtship between male morphs, which could influence their detectability. After the trial started, the Hogna and Schizocosa male were allowed to interact until the male was captured or until 45 min elapsed.

\section{Statistical analyses}

For all analyses of the field enclosures, the absence of an individual was used as a proxy for predation.

\section{Small field enclosures}

We report the mean \pm SE. All means were compared using an ANOVA. We compared the proportion of enclosures in which a female vs. male was preyed upon first to the expected proportion if predation was unbiased (i.e. $1 / 3$, the ratio of the number of females to the total number of spiders in the enclosures). We compared the proportion of enclosures in which a brushlegged vs. non-ornamented male was preyed upon first with the expected proportion if predation was unbiased (i.e. $1 / 2$, the ratio of the number of brush-legged males to the total number of males in the enclosures). To compare observed to expected ratios, we used the likelihood ratio test.

To compare predation among phenotypes (sexes and male morphs), we implemented a mixed model nominal logistic regression with phenotype, enclosure ID nested within substrate and time of day, and the interaction between phenotype and enclosure ID as the independent variables. The interaction term allowed us to determine whether patterns of predation varied across enclosures. Next, to determine if there was male morph-specific predation across environments, we implemented a mixed model nominal logistic regression with male morph, substrate, time of day, the interaction terms of substrate and time of day with male morph, and enclosure ID.

\section{Predator-prey interactions}

The time to the first attack and time to capture were compared between brush-legged and non-ornamented males, using Hogna ID as a random effect, in parametric survival analyses fitted with lognormal distributions. We used each Hogna in more than one trial and so included Hogna ID as an additional variable to control for individual variation among Hogna predators. We compared the likelihood of escaping a first attack and the likelihood of capture for brush-legged and non-ornamented males using nominal logistic regression with male morph as an independent variable and Hogna ID as a random effect. All statistical analyses were performed in jmp (JMP Version 6.0, SAS Institute Inc., Cary, NC, USA).

\section{Results}

\section{General observations}

In the small predator-absent enclosures, only two individuals out of $24(8 \%)$ were missing at the end of the 12-h trial, compared with 33 out of $70(47 \%)$ in predator-present enclosures. In the large predator-absent enclosures, no individuals were missing at the end of the 24-h trial. We therefore attributed the majority of missing spiders in the predator-present enclosures to predation by the Hogna spider and will therefore be referring to missing spiders as preyed upon. We observed Hogna eating Schizocosa on multiple occasions throughout both experiments (Table 1). In one instance (night/rock litter), we observed a Hogna simultaneously eating a female, a brush-legged male and a non-ornamented male. 
Table I. Live predation events by Hogna on Schizocosa observed real-time during censuses. Female symbols represent females preyed upon, filled male symbols represent brush-legged males preyed upon, open male symbols represent non-ornamented males preyed upon and '?' represent individuals that were too digested to identify.

\begin{tabular}{|c|c|c|c|c|}
\hline \multicolumn{2}{|c|}{ Leaf Litter } & \multicolumn{2}{|c|}{ Rock Litter } & \multirow{2}{*}{$\begin{array}{l}\text { Large } \\
\text { (Experiment 2) }\end{array}$} \\
\hline Day & Night & Day & Night & \\
\hline \multirow[t]{2}{*}{2 ㅇ } & 2 우 & $\begin{array}{l}1 \\
1 \\
\end{array}$ & $\begin{array}{l}2 \text { ○ } \\
4 \sigma^{x} \\
3 \sigma^{x}\end{array}$ & $\begin{array}{l}2 \sigma^{\top} \\
10^{\pi} \\
1 \text { ? }\end{array}$ \\
\hline & & & I? & \\
\hline
\end{tabular}

We never observed predation on Schizocosa by other animals (i.e. no bird predation or parasitism attempts by wasps or flies), and no cannibalism. We also observed no male-male fights.

Although only one male was observed courting during the experiments, in laboratory experiments copulation typically never occurs without courtship. Our observation of 12 copulations during the experiments thus suggests that males were courting at least intermittently throughout the experiment. Additionally, once males initiate courtship, they maintain the same rate of courtship independent of whether predator cues are present or absent (K. D. Fowler-Finn and E. A. Hebets, pers. obs.).

\section{Field Experiment 1: Small Enclosures}

Predation varied from $0 \%$ to $100 \%$ in the predatorpresent enclosures (mean $=47 \pm 8 \%, \mathrm{n}=12$ enclosures). Predation on females, brush-legged males and non-ornamented males each varied from $0 \%$ to $100 \%$.

Overall, predation did not differ between brushlegged and non-ornamented males, and this pattern was independent of enclosure ID, as indicated by the non-significant interaction between male morph and enclosure ID (Table 2; Figure 3). However, predation was dependent on both substrate and time of day, being greater at night and on rock litter (Table 2; Figure 4). The interaction term between substrate and time of day was non-significant $(p=0.9953)$ and was removed from the final model. As evidenced from the non-significant interaction terms of male morph and substrate and male morph and time of day, we did not detect morph-specific predation between substrates nor between times of day (Table 2; Figure 4). Predation did not differ between males and females, and this pattern was independent of enclosure ID (Table 2; Figure 3).
Table 2. Nominal logistic models testing for the effects of environment (substrate and time of day), male morph, and the interaction between environment and male morph, on predation. Bold entries indicates significance of $p<0.05$.

\begin{tabular}{|c|c|c|c|c|}
\hline \multicolumn{2}{|c|}{ Variable of interest Factor } & $d f$ & $x^{2}$ & $\mathrm{P}$ \\
\hline \multicolumn{5}{|c|}{ Small field enclosures } \\
\hline \multirow[t]{4}{*}{ Male morph } & Whole model & 25 & 42.96 & 0.2206 \\
\hline & Male morph & I & 2.76 & 0.0967 \\
\hline & $\begin{array}{l}\text { Enclosure ID (nested in } \\
\text { substrate and time of day) }\end{array}$ & 12 & 23.40 & 0.0245 \\
\hline & Male morph $\times$ Enclosure ID & 12 & 17.23 & 0.1410 \\
\hline \multirow[t]{7}{*}{ Environment } & Whole model & 17 & 32.05 & 0.0149 \\
\hline & Substrate & I & 7.64 & 0.0057 \\
\hline & Time of day & I & 15.26 & $<0.0001$ \\
\hline & Male morph & I & 0.51 & $0.477 I$ \\
\hline & Male morph×substrate & I & 0.35 & 0.5566 \\
\hline & Male morph $\times$ time of day & I & 0.06 & 0.8125 \\
\hline & $\begin{array}{l}\text { Enclosure ID (nested within } \\
\text { substrate and time of day) }\end{array}$ & 12 & 14.91 & 0.2465 \\
\hline \multirow[t]{4}{*}{ Spider sex } & Whole model & 25 & 34.75 & 0.0928 \\
\hline & Spider sex & I & 3.14 & 0.0762 \\
\hline & $\begin{array}{l}\text { Enclosure ID (nested in } \\
\text { substrate and time of day) }\end{array}$ & 12 & 30.52 & 0.0023 \\
\hline & Spider sex×enclosure ID & 12 & 10.97 & 0.5318 \\
\hline \multicolumn{5}{|c|}{ Large field enclosures } \\
\hline \multirow[t]{4}{*}{ Male morph } & Whole model & II & 10.36 & 0.4986 \\
\hline & Male morph & I & $<0.01$ & 0.9923 \\
\hline & Enclosure ID & 5 & 7.62 & 0.1782 \\
\hline & Male morph×enclosure ID & 5 & 2.65 & 0.7536 \\
\hline \multirow[t]{4}{*}{ Spider sex } & Whole model & 11 & 16.01 & 0.1408 \\
\hline & Spider sex & I & $<0.01$ & 0.9962 \\
\hline & Enclosure ID & 5 & 8.44 & 0.1336 \\
\hline & Spider sex $\times$ enclosure ID & 5 & 3.43 & 0.6334 \\
\hline
\end{tabular}

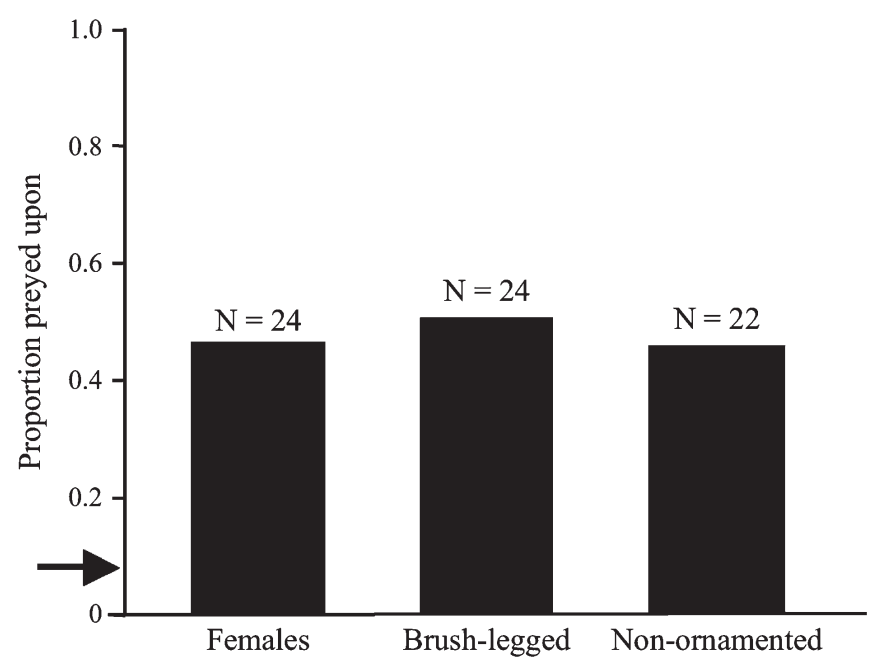

Figure 3. Predation across sex and male morph. Predation did not differ between females and males $(p=0.076)$ or between brushlegged and non-ornamented males $(p=0.097)$. The arrow indicates the baseline rate of disappearance of individuals in enclosures lacking the Hogna predator. 


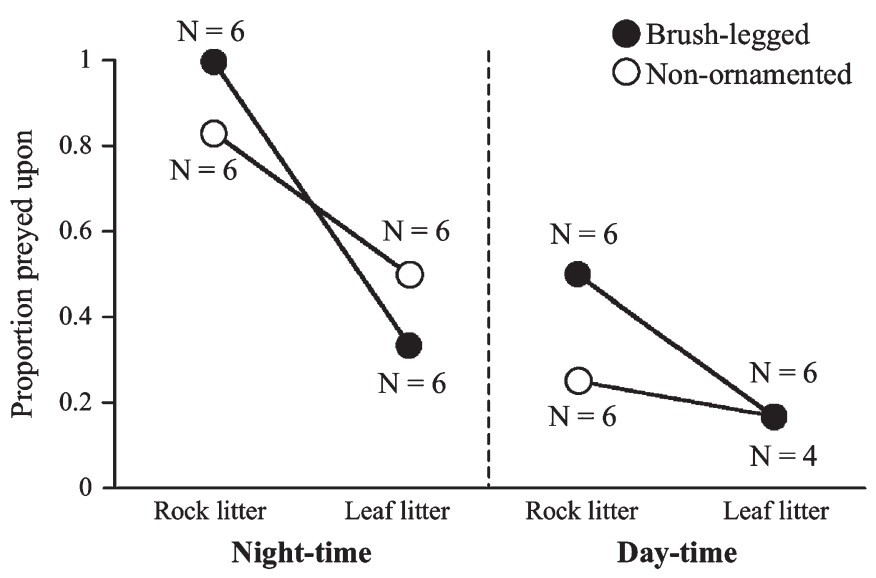

Figure 4. Male morph and substrate-dependent and time of daydependent predation. Brush-legged and non-ornamented males were preyed upon in equal proportions across all environmental conditions.

The hourly censuses allowed us to get a rough estimate of whether a male vs. female spider was preyed upon first in each enclosure, and whether a brushlegged vs. non-ornamented spider was preyed upon first in each enclosure. Excluding ties (instances where more than one spider had been preyed upon in between censuses), we found no bias in sex (likelihood ratio test: $\chi^{2}=0.87, \mathrm{p}=0.350, \mathrm{n}=10$ enclosures) or male morph (likelihood ratio test: $\chi^{2}=0.000, \mathrm{p}=1.00, \mathrm{n}=10$ enclosures) for the first spider preyed upon. Although we lacked statistical power to detect significant deviations from the expected, the effect size of the actual data show no difference between the two male morphs in which was preyed upon first (brush-legged, five enclosures; non-ornamented, five enclosures; ties, two enclosures.

\section{Field Experiment 2: Large Enclosures}

Predation in the large (leaf litter substrate) enclosures was comparable to the small leaf litter enclosures (average proportion preyed upon in large enclosures $=0.21 \pm 0.07, \mathrm{n}=6$ enclosures; average proportion preyed upon in small leaf litter only enclosures $=0.36 \pm 0.07, \mathrm{n}=8$ enclosures; $t(10)=1.57$, $\mathrm{p}=0.15)$.

Predation did not differ significantly between male morphs (brush-legged $=0.21, \mathrm{n}=24$ spiders; non-ornamented $=0.29, \mathrm{n}=24$ spiders; Table 2). Although predation was higher on males than females, this difference was not statistically significant (females $=0.08, \mathrm{n}=26$ spiders; males $=0.25, \mathrm{n}=48$ spiders; Table 2 ). When the
Table 3. Parametric survival analyses testing for differences between male morphs in the time to first attack and time to capture - censused data for individuals that were not attacked/captured are included in the models. Nominal logistic regressions testing for differences among male morphs in the likelihood of escaping first attack and likelihood of surviving capture by the end of the trial. Bold entries indicates significance of $p<0.05$. All experiments comply with University animal care regulations and comply with current laws of the United States.

\begin{tabular}{lllll}
\hline Variable of interest & Factor & df & $X^{2}$ & $P$ \\
\hline Time to attack & Whole model & 30 & 53.23 & $\mathbf{0 . 0 0 5 6}$ \\
& Male morph & I & 3.70 & $\mathbf{0 . 0 5 4 5}$ \\
& Hogna ID & 29 & 52.75 & $\mathbf{0 . 0 0 4 5}$ \\
Escape likelihood & Whole model & 28 & 55.20 & $\mathbf{0 . 0 0 1 6}$ \\
& Male morph & I & 3.85 & $\mathbf{0 . 0 4 9 6}$ \\
& Hogna ID (random term) & 27 & 53.82 & $\mathbf{0 . 0 0 1 6}$ \\
Capture likelihood & Whole model & 30 & 33.85 & 0.550 \\
& Male morph & I & 0.00 & 1.00 \\
& Hogna ID (random term) & 29 & 33.45 & 0.2604 \\
Time to capture & Whole model & 30 & 79.59 & $<\mathbf{0 . 0 0 0 ~ I ~}$ \\
& Male morph & I & 0.05 & 0.8224 \\
& Hogna ID & 29 & 79.48 & $<\mathbf{0 . 0 0 0}$ I
\end{tabular}

interaction term was removed from the model for increased power, difference between males and females remained marginally non-significant $(p=0.0638)$.

\section{Experiment 3: Predator-Prey Interactions}

Size and developmental status did not influence Hogna capture success ( $\mathrm{p}>0.8$ for both analyses). Interactions with mature female Hogna did not differ from those with immature female Hogna: time to first attack, the probability of surviving the first attack, and the time to capture did not differ between mature and immature Hogna ( $p>0.4$ for all analyses).

Attacks occurred in 48 of the 51 trials (two brushlegged males and one non-ornamented male were not attacked). Twenty-eight of 48 first attacks (58\%) resulted in capture of the Schizocosa male. Brush-legged males were attacked sooner than non-ornamented males, and were more likely to survive first attacks than non-ornamented males (Figures 5 \& 6; Table 3). The male morphs did not differ in the time to capture, or the likelihood of being captured (Table 3; Figures $5 \& 6$ ).

The two male morphs did not differ in weight (nonornamented $=0.0555 \pm 0.0022 \mathrm{~g}, \mathrm{n}=23$, brush-legged $=$ 


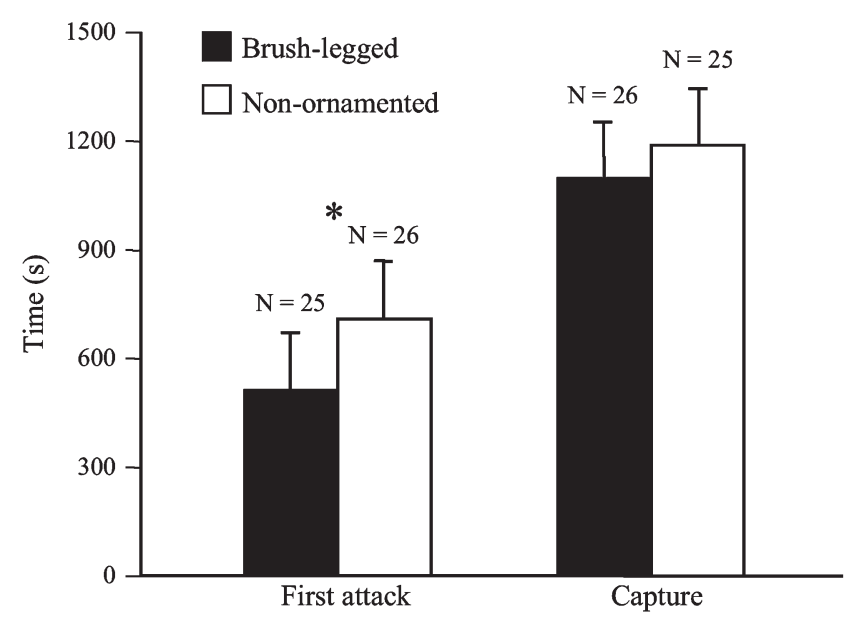

Figure 5. Attack and capture latencies. Brush-legged males were attacked sooner than non-ornamented males, but time to capture did not differ between male morphs. Means shown in the figure are least-mean squares derived from a mixed model including predator ID as a random effect, including individuals that were never attacked or captured as values representing the maximum trial length.

$\left.0.0542 \pm 0.0022, \mathrm{n}=24, F_{1,45}=0.173, \mathrm{p}=0.680\right)$. Weight did not influence the likelihood of escaping the first attack $(p=0.980)$, or the likelihood of being captured by the end of the trial $(p=0.274)$.

\section{Discussion}

Using two syntopic morphs of Schizocosa wolf spiders (brush-legged and non-ornamented males), we examined the relationship between male secondary sexual traits and incurred predation by a predatory spider measured in the field and laboratory. We also examined risk of predation and antipredatory escapes associated with each morph. Despite previously documented difference in conspicuousness between the two male phenotypes (Pruden \& Uetz 2004; Roberts et al. 2007; Roberts \& Uetz 2008), we found no difference in realized rates of predation on brush-legged vs. non-ornamented males in field enclosures. Although predation was dependent on both substrate and time of day, we found no environment-dependent differences in predation between morphs. Results from staged laboratory trials support field results and similarly showed no difference between the male morphs in either incurred predation or time to capture. However, brush-legged males were attacked more quickly than non-ornamented males, but were more likely to escape first attacks. Brush-legged males thus appeared to compensate for greater predation risk by an increased ability to escape attacks.

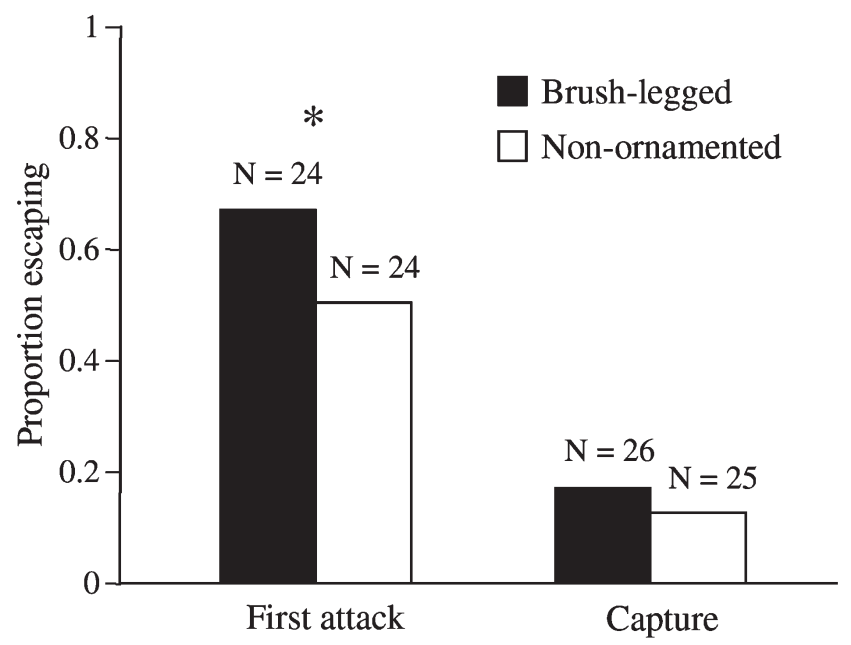

Figure 6. Attack and capture likelihoods. Brush-legged males were more likely to escape first attacks, but both male morphs were equally like to be captured by the end of the trial. $N$ values for attack likelihoods are lower than the number of trials because three individuals were never attacked.

We found no relationship between predation-caused mortality and sexual ornamentation and behavior in either the field or laboratory trials. Results from our second experiment using larger enclosures with natural representations of prey to predator ratios mirrored those of the small enclosure experiment, and our laboratory trials also showed equal captures of both male morphs, thus providing multiple lines of evidence that predation by Hogna exerts equal mortality on brushlegged and non-ornamented males. Results from our staged single predator-prey laboratory trials further support equal mortality by Hogna for brush-legged and non-ornamented males-the two male morphs were captured equally, both with respect to the likelihood of capture and the time to capture.

Studies across taxa have demonstrated higher predation on more ornamented/conspicuous males that are often favored by female choice-more brightly colored guppies suffer higher attacks and captures by visually hunting fish predators (Godin \& McDonough 2003), male damselflies with larger sexually selected melanized wing patches show higher estimates of predation-induced mortality (Svensson \& Friberg 2007), male wolf spiders actively searching and courting and those with higher rates of courtship suffer increased predation (Kotiaho et al. 1998; Lindstrom et al. 2006; Hoefler et al. 2008), and brighter models of male lizards are attacked by avian predators more frequently (Stuart-Fox et al. 2003). In these cases, mortality costs vary with sexual ornamentation/courtship, and it is 
possible that other predators of Schizocosa may exert differential mortality on brush-legged vs. non-ornamented males. However, in general, predation costs associated with secondary sexual traits may not be as straightforward as increased mortality. The conspicuousness of signaling animals can vary greatly with background and ambient light (Endler 1991; Endler \& Thery 1996; Stuart-Fox et al. 2003; Cummings et al. 2008), and so the environment may influence which males are more conspicuous to predators. In addition, males may exhibit anti-predator behaviors that can influence detection and capture (Edmunds 1974; Lind \& Cresswell 2005), which is masked by strictly measuring mortality.

Our results speak directly to the importance of environment on predation - we found significant environment-specific predation risk with the highest predation rates occurring on rock litter and at night. Substratedependent signal/cue transmission can force predators to rely on different signals/cues across substrates, and displays can be differentially detectable among environments (Endler 1993). Rocks dramatically reduce the transmission of vibration signals (Elias et al. 2004), whereas complex leaf litter may reduce transmission of visual signals (relative to rocks). However, despite brush-legged males displaying more visually and non-ornamented males displaying more vibrationally (Hentz 1844; Uetz \& Denterlein 1979; Uetz \& Dondale 1979), we found no morph-specific predation across substrates. Higher predation on rocks is likely explained by the limited vertical structure in the rock litter, ultimately providing less cover than the more complex, deeper leaf litter. In contrast, the higher predation at night is most easily interpreted in terms of the basic activity patterns of both predator and prey Schizocosa are both diurnally and nocturnally active but occupy the upper surface of the substrate during the night (K.D. Fowler-Finn and E.A. Hebets, pers. obs.), and, although Hogna are capable of hunting during the day, they mostly remain in burrows during the day and emerge at night to forage (Walker 1999; Walker \& Rypstra 2003).

In the staged laboratory trials allowing us to examine predator-prey interactions, brush-legged males were attacked sooner than non-ornamented males, and were more likely to escape attacks. Our observed shorter time to attack for brush-legged males is consistent with previous video-playback studies demonstrating quicker orientation and attack times on brushlegged vs. non-ornamented males by various predators (Pruden \& Uetz 2004; Roberts et al. 2007; Roberts \&
Uetz 2008). Our data, however, demonstrate that although brush-legged males are more conspicuous than non-ornamented males, this increased conspicuousness does not necessarily translate into increased mortality - brush-legged males compensate for an increased risk of attack by escaping attacks more often, leading to similar predator-mediated mortality (via wolf spider predators).

Predation is known to be important in shaping the behavior of many animals (Lima \& Dill 1990; Lima 1998), and the increased escape ability of brush-legged males may have been shaped by their increased predation risk. Variation in predation pressure has been implicated in influencing escape behaviors in lizards (Husak \& Rouse 2006), and selection has resulted in covariation of escape behavior and morphological phenotype in garter snakes (Brodie 1992). Despite increased short-term survival, however, these behaviors can have longer term negative fitness effects in terms of lost foraging and reproductive opportunities (Dill \& Fraser 1997; Persons et al. 2002; Cresswell 2008; Chelini et al. 2009) and increased energetic costs required by escapes (Lima 1998). Therefore, the increased risk of attack coupled with increased escapes may represent greater costs to brush-legged males.

Other behaviors in addition to escape ability may influence the mortality incurred by brush-legged and nonornamented males. Many organisms can decrease their likelihood of detection and attack by predators by altering locomotory and/or courtship behavior in response to the level of the threat of predation (Dill \& Fraser 1997; Sih 1997; Puttlitz et al. 1999; Persons \& Rypstra 2001; Persons et al. 2001, 2002; Downes 2002; Templeton \& Shriner 2004; Folz et al. 2006). Although we did not test for these types of behaviors, the two male morphs may be able to alter predation costs by adjusting their behavior patterns when the risk of predation is high. Sex-specific behaviors may help explain why we could not confirm sex-specific mortality in our field enclosure studies (despite trends of higher predation on males in the large field enclosures). Future studies examining the plasticity of behavior across environments with varying predation risk are now needed, in addition to studies examining sex-specific mortality.

Predation is assumed to be a prevalent natural selective force balancing sexual selection. However, surprisingly few studies have directly tested predation on displaying males and even fewer have tested predation on sexually selected traits in the field under natural or even semi-natural environmental conditions. Because field conditions can vary drastically from lab- 
oratory conditions, it is critical to utilize field-based approaches before making conclusions about the impact of predation on the evolution of sexually selected traits. Here, we provide a comprehensive test of costs arising from secondary sexual traits, testing for direct mortality costs, increased risk of predation, and behaviors that may compensate for predation risk. We find that, across environmental conditions, mortality costs by an important predator do not differ between two male morphs with very different ornamentation and courtship displays. Brush-legged males suffer increased risk of predation in the form of quicker attacks by Hogna, for which they compensate by escaping better. Overall, although brush-legged males experience greater risk associated with predation, they are able to compensate by a higher likelihood of escaping an attack, resulting in equal realized rates of predation in the field. Through a series of comprehensive tests, we show that costs of predation do not show a straightforward relationship with secondary sexual traits, and are mediated through behavioral interactions between predator and prey.

Acknowledgments - We would like to thank Jeremy Brozek, Pat Miller, Gail Stratton and Aaron Rundus for assistance collecting animals. Dustin Franklin, Morgan Campbell, Nicole Samuels and Sue Fowler-Finn aided in animal care. Tom Miller and Steven Schwartz helped with marking individuals. Staff at the University of Mississippi Greenhouse allowed us to collect and conduct the field trials. Gail Stratton and Pat Miller provided housing and invaluable advice during experimentation. Bill Wagner, Jay Storz, Dan Leger, Rafael Rodriguez, Laura Sullivan Beckers, Dustin Wilgers, Steven Schwartz, Mitch Bern, Mari Pesek, Darren Rebar, and three anonymous reviewers provided feedback that greatly improved this manuscript. Monetary support was provided by a National Science Foundation Graduate Fellowship to K. D. Fowler-Finn and an Initiative for Ecological and Evolutionary Analysis Research Grant In-Aid-Of, School of Biological Sciences, University of Nebraska to K. D. Fowler-Finn.

\section{Literature Cited}

Alcock, J. 1995: Persistent size variation in the Anthophorine bee Centris-Pallida (Apidae) despite a large male mating advantage. Ecol. Entomol. 20, I-4.

Alcock, J. 1996: Male size and survival:The effects of male combat and bird predation in Dawson's burrowing bees, Amegilla daw- soni. Ecol. Entomol. 21, 309-316.

Andersson, M. 1994: Sexual Selection. Princeton Univ. Press, Princeton, NJ.

Brodie, E. D. 1992: Correlational selection for color pattern and antipredator behavior in the garter snake Thamnophis-ordinoides. Evolution 46, 1284-1298.

Burk, T. 1982: Evolutionary Significance of predation on sexually signalling males. Florida Entomol. 65, 90-104.

Cade, W. 1975: Acoustically orienting parasitoids: Fly phonotaxis to cricket song. Science 190, 1312-1313.

Candolin, U. 1998: Reproduction under predation risk and the trade-off between current and future reproduction in the threespine stickleback. Proc. R. Soc. Lond. B Biol. Sci. 265, | |7|-| |75.

Chelini, M. C., Willemart, R. H., \& Hebets, E. A. 2009: Costs and benefits of freezing behaviour in the harvestman Eumesosoma roeweri (Arachnida, Opiliones). Behav. Proc. 82, I53-159.

Cresswell, W. 2008: Non-lethal effects of predation in birds. Ibis I50, 3-17.

Cummings, M. E., Jordao, J. M., Cronin, T.W., \& Oliveira, R. F. 2008: Visual ecology of the fiddler crab, Uca tangeri: Effects of sex, viewer and background on conspicuousness. Anim. Behav. 75, 175-188.

Delaney, K. J., Roberts, J. A., \& Uetz, G.W. 2007: Male signaling behavior and sexual selection in a wolf spider (Araneae: Lycosidae): A test for dual functions. Behav. Ecol. Sociobiol. 62, 67-75.

Dill, L. M., \& Fraser, A. H. G. 1997:The worm re-turns: Hiding behavior of a tube-dwelling marine polychaete, Serpula vermicularis. Behav. Ecol. 8, 186-193.

Downes, S. J. 2002: Does responsiveness to predator scents affect lizard survivorship? Behav. Ecol. Sociobiol. 52, 38-42.

Edmunds, M. 1974: Defence in Animals: A Survey of Antipredator Defences. Longman Group Limited, Harlow.

Elias, D. O., Mason, A. C., \& Hoy, R. R. 2004:The effect of substrate on the efficacy of seismic courtship signal transmission in the jumping spider Habronattus dossenus (Araneae: Salticidae). J. Exp. Biol. 207, 4I05-4I 10.

Endler, J. A. 1980: Natural selection on color patterns in Poecilia reticulata. Evolution 34, 76-91.

Endler, J.A. 1983: Natural and sexual selection on color patterns in Poeciliid fishes. Environ. Biol. Fish 9, 173-190.

Endler, J.A. 1991:Variation in the appearance of guppy color patterns to guppies and their predators under different visual conditions. Vision Res. 31, 587-608.

Endler, J. A. 1992: Signals, signal conditions, and the direction of evolution. Am. Nat. 139, SI25-SI53.

Endler, J.A. 1993: Some general-comments on the evolution and design of animal communication-systems. Phil. Trans. R. Soc. Lond., B. Biol. Sci. 340, 2I5-225. 
Endler, J.A., \& Thery, M. 1996: Interacting effects of lek placement, display behavior, ambient light, and color patterns in three neotropical forest-dwelling birds. Am. Nat. 148, 42 I-452.

Foelix, R. F. 1996:The Biology of Spiders. Oxford Univ. Press, Inc., New York, USA.

Folz, H. C., Wilder, S. M., Persons, M. H., \& Rypstra, A. L. 2006: Effects of predation risk on vertical habitat use and foraging of Pardosa milvina. Ethology I I 2, I I52-1 I 58.

Fowler-Finn, K. D. 2009: Exploring the maintenance of and selection on two distinct male morphs in a Schizocosa wolf spider. Ph.D. Dissertation. University of Nebraska, Lincoln, NE.

Godin, J. G. J. 1995: Predation risk and alternative mating tactics in male Trinidadian Guppies (Poecilia reticulata). Oecologia 103, 224-229.

Godin, J. G. J., \& McDonough, H. E. 2003: Predator preference for brightly colored males in the guppy:A viability cost for a sexually selected trait. Behav. Ecol. 14, 194-200.

Hebets, E. A., \& Vink, C. J. 2007: Experience leads to preference: Experienced females prefer brush-legged males in a population of syntopic wolf spiders. Behav. Ecol. 18, 765-771.

Hentz, N. M. 1844: Descriptions and figures of the araneides of the United States. Boston J. Nat. Hist. 4, 386-396.

Hoefler, C. D., Persons, M. H., \& Rypstra, A. L. 2008: Evolutionarily costly courtship displays in a wolf spider:A test of viability indicator theory. Behav. Ecol. 19, 974-979.

Husak, J. F., \& Rouse, M. N. 2006: Population variation in escape behavior and limb morphology of collared lizards (Crotaphytus collaris) in Oklahoma. Herpetologica 62, 156-163.

Husak, J. F., Macedonia, J. M., Fox, S. F., \& Sauceda, R. C. 2006: Predation cost of conspicuous male coloration in collared lizards (Crotaphytus collaris): An experimental test using claycovered model lizards. Ethology I I2, 572-580.

Kotiaho, J. S. 200I: Costs of sexual traits: A mismatch between theoretical considerations and empirical evidence. Biol. Rev. 76, 365-376.

Kotiaho, J., Alatalo, R. V., Mappes, J., Parri, S., \& Rivero, A. 1998: Male mating success and risk of predation in a wolf spider:A balance between sexual and natural selection? J. An. Ecol. 67, 287-29l.

Kwiatkowski, M. A. 2003: Variation in conspicuousness among populations of an iguanid lizard, Sauromalus obesus (= ater). Copeia 48I-492.

Lima, S. L. 1998: Nonlethal effects in the ecology of predatorprey interactions - what are the ecological effects of antipredator decision-making? Bioscience 48, 25-34.

Lima, S. L., \& Dill, L. M. 1990: Behavioral decisions made under the risk of predation - a review and prospectus. Can. J. Zool. 68, 619-640.

Lind, J., \& Cresswell, W. 2005: Determining the fitness consequences of antipredation behavior. Behav. Ecol. 16, 945-956.
Lindstrom, L., Ahtiainen, J. J., Mappes, J., Kotiaho, J. S., Lyytinen, A., \& Alatalo, R. V. 2006: Negatively condition dependent predation cost of a positively condition dependent sexual signalling. J. Evol. Biol. 19, 649-656.

Magnhagen, C. 1991: Predation risk as a cost of reproduction. Trends Ecol. Evol. 6, I83-185.

Marshall, S. D., \& Rypstra, A. L. 1999: Spider competition in structurally simple ecosystems. J.Arachnol. 27, 343-350.

McClintock, W. J., \& Uetz, G.W. 1996: Female choice and pre-existing bias: Visual cues during courtship in two Schizocosa wolf spiders (Araneae: Lycosidae). Anim. Behav. 52, 167-181.

Persons, M. H., \& Rypstra, A. L. 200I:Wolf spiders show graded antipredator behavior in the presence of chemical cues from different sized predators. J. Chem. Ecol. 27, 2493-2504.

Persons, M. H., Walker, S. E., Rypstra, A. L., \& Marshall, S. D. 200 I: Wolf spider predator avoidance tactics and survival in the presence of diet-associated predator cues (Araneae : Lycosidae).Anim. Behav. 61, 43-51.

Persons, M. H., Walker, S. E., \& Rypstra, A. L. 2002: Fitness costs and benefits of antipredator behavior mediated by chemotactile cues in the wolf spider Pardosa milvina (Araneae: Lycosidae). Behav. Ecol. 13, 386-392.

Pruden, A. J., \& Uetz, G.W. 2004: Assessment of potential predation costs of male decoration and courtship display in wolf spiders using video digitization and playback. J. Insect Behav. 17,67-80.

Puttlitz, M. H., Chivers, D. P., Kiesecker, J. M., \& Blaustein, A. R. 1999: Threat-sensitive predator avoidance by larval pacific treefrogs (Amphibia, Hylidae). Ethology 105, 449-456.

Roberts, J.A., \& Uetz, G.W. 2008: Discrimination of variation in a male signaling trait affects detection time in visual predators. Ethology I 14, 557-563.

Roberts, J. A., Taylor, P.W., \& Uetz, G. W. 2007: Consequences of complex signaling: Predator detection of multimodal cues. Behav. Ecol. 18, 236-240.

Ryan, M. J., \& Tuttle, M. D. 1982: Bat predation and sexual advertisement in a neotropical anuran. Am. Nat. 119, 136-139.

Rypstra, A. L., \& Samu, F. 2005: Size dependent intraguild predation and cannibalism in coexisting wolf spiders (Araneae, Lycosidae). J.Arachnology 33, 390-397.

Scheffer, S. J., Uetz, G.W., \& Stratton, G. E. 1996: Sexual selection, male morphology, and the efficacy of courtship signalling in two wolf spiders (Araneae: Lycosidae). Behav. Ecol. Sociobiol. 38, 17-23.

Sih, A. 1997: To hide or not to hide? Refuge use in a fluctuating environment. Trends Ecol. Evol. 12, 375-376.

Stratton, G. E., \& Uetz, G.W. 1981: Acoustic communication and reproductive isolation in two species of wolf spiders (Araneae: Lycosidae). Science 214, 575-576.

Stuart-Fox, D. M., Moussalli, A., Marshall, N. J., \& Owens, I. P. F. 
2003: Conspicuous males suffer higher predation risk: Visual modelling and experimental evidence from lizards. Anim. Behav. 66, 54I-550.

Stuart-Fox, D. M., Moussalli, A., Johnston, G. R., \& Owens, I. P. F. 2004: Evolution of color variation in dragon lizards: Quantitative tests of the role of crypsis and local adaptation. Evolution 58, I549-1559.

Svensson, E. I., \& Friberg, M. 2007: Selective predation on wing morphology in sympatric damselflies. Am. Nat. I70, I0I-II 2.

Templeton, C. N., \& Shriner,W. M. 2004: Multiple selection pressures influence Trinidadian guppy (Poecilia reticulata) antipredator behavior. Behav. Ecol. 15, 673-678.

Uetz, G.W., \& Denterlein, G. 1979: Courtship behavior, habitat, and reproductive isolation in Schizocosa rovneri

Uetz and Dondale (Araneae: Lycosidae). J.Arachnol. 7, I2I-128.

Uetz, G.W., \& Dondale, C. D. 1979: A new wolf spider in the genus Schizocosa (Araneae: Lycosidae) from Illinois. J. Arachnol. 7, 86-88.
Uetz, G.W., \& Roberts, J. A. 2002: Multisensory cues and multimodal communication in spiders: Insights from video / audio playback studies. Brain Behav. Evol. 59, 222-230.

Wagner, J. D., \& Wise, D. H. 1996: Cannibalism regulates densities of young wolf spiders: Evidence from field and laboratory experiments. Ecology 77, 639-652.

Walker, S. E. 1999: The effect of feeding history on retreat construction in the wolf spider Hogna helluo (Walckenaer). J. Arachnol. 27, 689-69l.

Walker, S. E., \& Rypstra, A. L. 2003: Sexual dimorphism and the differential mortality model: Is behaviour related to survival? Biol. J. Linn. Soc. 78, 97-103.

Zuk, M., \& Kolluru, G. R. 1998: Exploitation of sexual signals by predators and parasitoids. Q. Rev. Biol. 73, 4I5-438.

Zuk, M., Rotenberry, J. T., \& Tinghitella, R. M. 2006: Silent night: Adaptive disappearance of a sexual signal in a parasitized population of field crickets. Biol. Lett. 2, 52I-524. 